\title{
Bilobed intramedullary and extramedullary bronchogenic cyst of the conus medullaris: illustrative case
}

\author{
Barry Ting Sheen Kweh, MBBS (Hons), ${ }^{1,3}$ Samuel Roberts-Thomson, MBBS, FRCPA, ${ }^{2}$ Thomas Verhellen, BSc, ${ }^{4}$ and \\ Girish Nair, MBBS, MCh, FRACS ${ }^{1,5}$ \\ Departments of ${ }^{1}$ Neurosurgery and ${ }^{2}$ Anatomical Pathology, Royal Melbourne Hospital, Parkville, Victoria, Australia; ${ }^{3}$ National Trauma Research Institute, Melbourne, Victoria \\ Australia; ${ }^{4}$ Neurophysiology Services Australia, New South Wales, Australia; and ${ }^{5}$ Department of Surgery, University of Melbourne, Parkville, Victoria, Australia
}

\begin{abstract}
BACKGROUND Spinal bronchogenic cysts are rare nonneoplastic congenital variants of neurenteric cysts. The natural history and surgical management of these lesions are poorly understood.

OBSERVATIONS A 25-year-old male presented with progressive back pain and bilateral lower limb sciatica of 6 months' duration. He had undergone subtotal resection of an intramedullary bronchogenic conus medullaris cyst 5 years prior. Magnetic resonance imaging revealed a recurrent bilobed intramedullary and extramedullary conus medullaris cystic lesion. The authors resected the lesion via a posterior approach with the aid of intraoperative neuromonitoring. Gross total resection was precluded by the tightly adherent nature of the cyst and the fact that stimulation of a residual intramedullary portion of the lesion evoked external anal sphincter responses.
\end{abstract}

LESSONS This is the first reported case of a bilobed intramedullary and extramedullary bronchogenic cyst of the conus medullaris. This unique case lends insight into the poorly defined embryogenesis of bronchogenic cysts by favoring the split notochord syndrome theory rather than the ectopic ectoderm proposal. The importance of neuromonitoring when resecting these tightly adherent lesions is demonstrated. Finally, although the secretory nature of these lesions portends a tendency for cyst reaccumulation, it is imperative to recognize that this is usually a slow process.

https://thejns.org/doi/abs/10.3171/CASE21323

KEYWORDS bronchogenic cyst; intramedullary; extramedullary; neurenteric cyst; neuromonitoring; conus medullaris

Spinal bronchogenic cysts are rare nonneoplastic variants of neurenteric cysts usually located in the extramedullary compartment of the cervical and thoracic regions of the spinal cord..$^{1-3}$ We report the first case of a simultaneously intramedullary and extramedullary bronchogenic cyst of the conus medullaris.

\section{Illustrative Case}

A 24-year-old male presented with a 6-month history of progressively worsening back and bilateral lower limb radicular pain to the anteromedial thighs. He had no sphincter disturbance. He had undergone subtotal resection of an $\mathrm{L} 1$ intradural intramedullary bronchogenic cyst via L1-3 laminectomy 5 years prior. The finding of his lower limb neurological examination was unremarkable with Medical Research Council 5/5 power in all myotomes.
Sensation to crude touch, including in the perineal and perianal regions, was preserved.

Magnetic resonance imaging (MRI) of his lumbar spine revealed a bilobed dual-compartment intramedullary and extramedullary cyst at L1. The larger $18 \times 19 \times 29$-mm posteroinferior component was extramedullary, whereas the smaller anterosuperior component was intramedullary (Fig. 1). The entire lesion was hypointense on a T1-weighted sequence and hyperintense on a T2-weighted sequence with minimal gadolinium enhancement. Computed tomography demonstrated bony remodeling consistent with the known chronicity of this cystic lesion. MRI of the remainder of his neuraxis revealed a $57-\mathrm{mm}$ small-caliber long-segment cervical syrinx from C4-T1, likely secondary to this lumbar lesion.

The patient underwent near-total resection of the recurrent cyst via a posterior approach. An encapsulated, thin-walled cyst filled with clear,

ABBREVIATIONS CMAP = compound muscle action potential; MRI = magnetic resonance imaging; tEMG = triggered electromyography . INCLUDE WHEN CITING Published August 9, 2021; DOI: 10.3171/CASE21323

SUBMITTED May 24, 2021. ACCEPTED June 14, 2021.

(C) 2021 The authors, CC BY-NC-ND 4.0 (http://creativecommons.org/licenses/by-nc-nd/4.0/). 

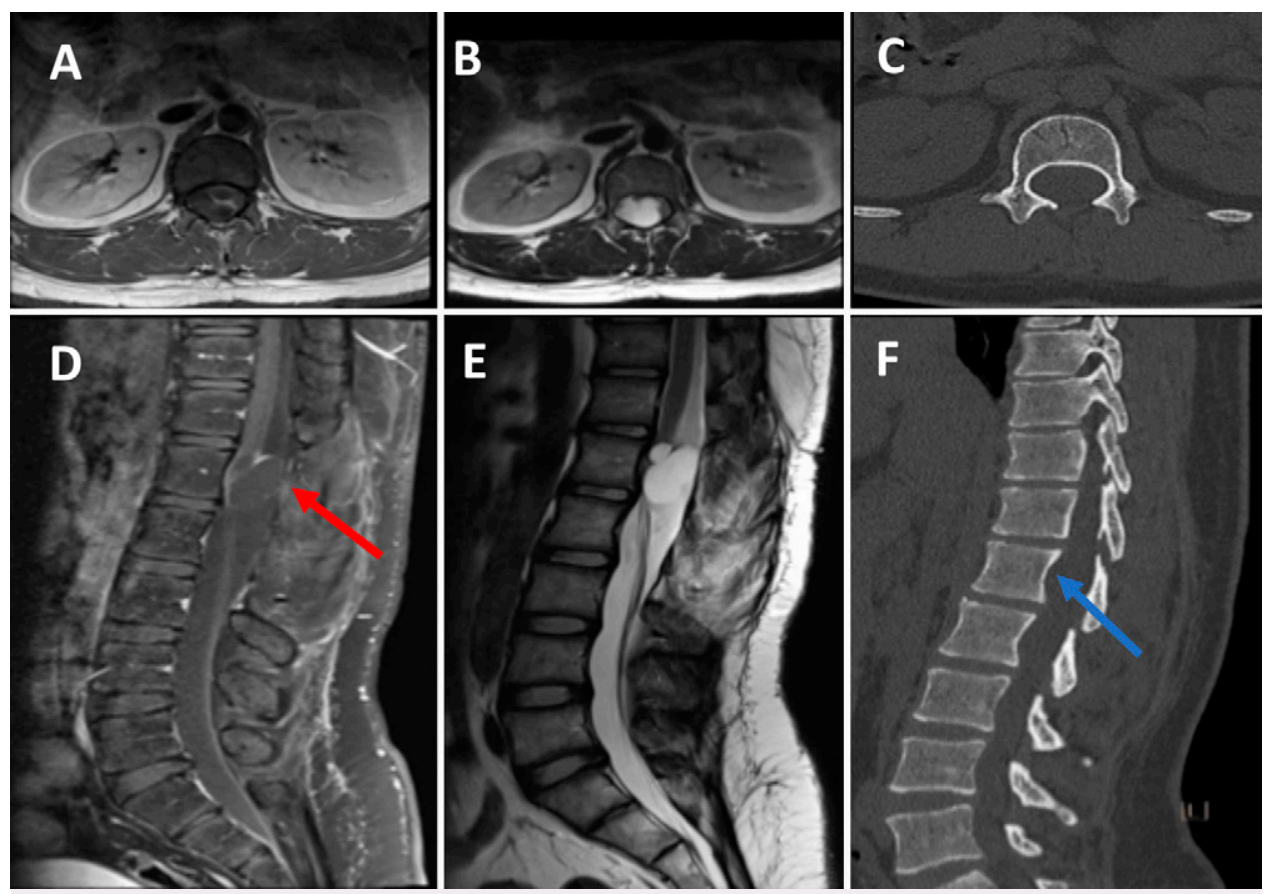

FIG. 1. Preoperative MRI of the lumbar spine. Axial sequences show a T1 hypointense (A) and T2 hyperintense (B) bilobed cystic lesion with evidence of intramedullary and extramedullary extension visible on the sagittal T1 (D) and T2 (E) views. There is ventral displacement of the conus medullaris caused by the extramedullary component, with some posterior wall enhancement visible on the postcontrast T1 sequence (red arrow). Computed tomography axial (C) and sagittal (F) reformats show bony remodeling (blue arrow) reflecting the chronicity of this cystic lesion.

gelatinous fluid was encountered (Fig. 2). During resection, components of the lesion were stimulated to investigate proximity to and involvement of neural elements. Triggered electromyography (tEMG) stimulation was performed using a concentric bipolar stimulation probe (Spes Medica, Genova, Italy) with stimulation between 2 and $4 \mathrm{~mA}, 2 \mathrm{~Hz}, 200-\mu$ sec duration, and a single-pulse stimulus. ${ }^{4}$ Initial stimulation before resection recorded compound muscle action potentials (CMAPs) from the right vastus lateralis $(300-600$ $\mu \mathrm{V}$ ) and tibialis anterior (50 and $300 \mu \mathrm{V}$ ), as well as low-amplitude CMAPs on the external anal sphincter (approximately $40 \mu \mathrm{V}$ ). Residual tumor was stimulated using the aforementioned parameters with CMAP responses recorded on the external anal sphincter $(78 \mu \mathrm{V})$, left vastus lateralis $(41 \mu \mathrm{V})$, and left tibialis anterior $(23 \mu \mathrm{V})$. A thin rim of tissue posteriorly was deliberately preserved, given that stimulation of this portion evoked anal sphincter responses of higher recorded amplitudes $(40 \mu \mathrm{V}$ versus $78 \mu \mathrm{V})$ than initial stimulation (Fig. 3).

Histopathological analysis confirmed a cyst lined by pseudostratified, ciliated columnar epithelium with surrounding fibroadipose tissue containing mucus and serous-type glands consistent with the bronchogenic variant of neurenteric cysts (Fig. 2). No glial tissue or evidence of malignancy was observed. The patient experienced complete symptom resolution postoperatively and was neurologically intact. MRI on day 3 after surgery demonstrated complete resection of the extramedullary component and significant reduction in the size of the enhancing intramedullary component (Fig. 4). On clinical review 11 months later, he remained clinically stable, but there was slight interval recurrence of the residual intramedullary cystic lesion. Ongoing surveillance is planned.

\section{Discussion}

\section{Observations}

Neurenteric cysts, or enterogenous cysts, constitute only $0.3 \%-1.3 \%$ of all spinal cord tumors and exhibit a preponderance for male patients and those in their second and third decades of life. ${ }^{5}$ Although there have been many reports of intradural extramedullary lesions, true intramedullary cysts are rare and found in only $5 \%$ of cases. ${ }^{6-10}$ When lined by respiratory-like, pseudostratified, ciliated epithelium, these lesions are termed "bronchogenic cysts." Histopathologically, Wikins and Odom ${ }^{11}$ categorized neurenteric cysts into three subtypes: Category $A$ cysts were simply lined by epithelium with a basement membrane, category $B$ lesions contained gastrointestinal or tracheobronchial-like tissue, and category $C$ lesions possessed intrinsic ependymal or glial tissue. ${ }^{11,12}$ In our comprehensive literature review of the MEDLINE, Embase, Google Scholar, and Cochrane databases, we found only three previously reported cases of intramedullary bronchogenic cysts (Table 1). To our knowledge, this is the first report of a bilobed, simultaneously intramedullary and extramedullary bronchogenic cyst and likely provides new insight into the poorly defined embryological origin of these rare lesions.

There are several competing hypotheses regarding the development of bronchogenic cysts. It is known that during the third week of embryogenesis, the ectoderm-lined amniotic cavity and endoderm-lined yolk sac are transiently connected via the neurenteric canal, which is later replaced by the notochord. ${ }^{6,13,14}$ The proposed mechanisms behind the formation of these foregut duplication cysts 

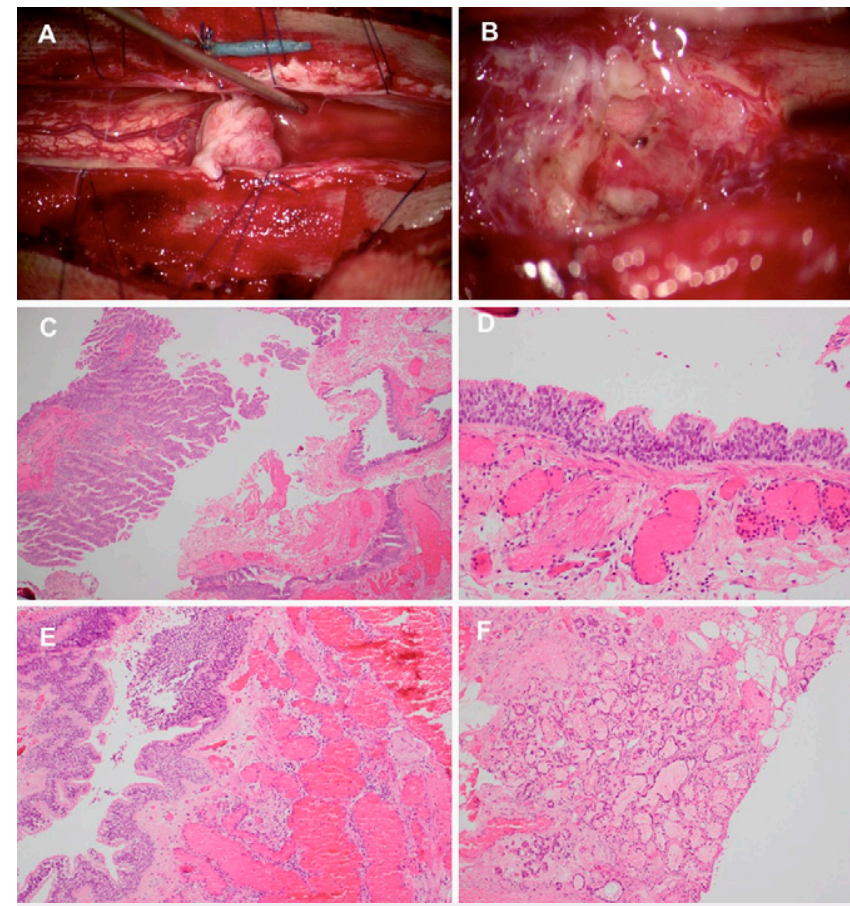

FIG. 2. Intraoperative view (A) of the cyst showing both a solid and a cystic component filled with clear, gelatinous fluid. Cerebrospinal fluid flow was reestablished after resection (B). Hematoxylin and eosin stain demonstrating at low power $(\times 4$ power $)$ a partially disrupted cyst with a pseudostratified epithelial lining that forms tufts into the cyst lumen (C). Higher magnification ( $\times 20$ power) shows the cyst lining to have prominent cilia (D). The cyst walls $(\times 10$ power) contain prominent dilated and congested capillaries $(\mathbf{E})$ in some areas, as well as serous and mucinous glands with some adipose tissue in others (F).

are (1) Bentley and Smith's ${ }^{15}$ split notochord syndrome theory, which argues that incomplete partitioning of the notochord leads to ventral herniation of endodermal tissue; (2) incomplete separation of the germ layer due to ectodermal-endodermal adhesion; (3) persistent or accessory neurenteric canal of Kovalevsky, thereby providing a fistula for endodermal tissue; (4) incomplete excalation of the notochord; and (5) ectopic endoderm. ${ }^{5,15,16}$ The fact that the cyst in our case was simultaneously within the intramedullary and extramedullary compartments provides new evidence in support of the split notochord syndrome, involving accessory notochord or adhesions causing failure of the ectodermal-endodermal layers to separate. The notion of ectopic ectoderm seems less likely, given that this would not account for the transmedullary nature of the cyst in our case.

It is important to acknowledge that previous surgery may in part account for the imaging appearances of the bilobed cyst in our case. However, we still favor this to be a primary rather than iatrogenic occurrence for three reasons. First, intraoperatively, the cyst seemed to be anchored in both intramedullary and extramedullary spaces and was tightly adherent at all points. The cyst did not appear to originate from one compartment, either intramedullary or extramedullary, and herniate into the other. Second, MRI of the bilobed cyst identified the only site of thin rim enhancement actually at the angulated junction between the intramedullary and extramedullary components of the cyst (Fig. 1). At this transmedullary border was located the only $\mathrm{T} 1$ hyperintensity shown on imaging, highly suggestive of this as the primary focus of the lesion. Third, we could find only a single report of extramedullary adhesions from prior surgery causing the formation of an intramedullary cyst over time. ${ }^{17}$ Larger case series of this rare lesion with comprehensive documentation of evolution over time would be of great value.

Gross total resection remains the mainstay of management, given that it is primarily mass effect on the spinal cord that leads to neurological deficit. ${ }^{18-20}$ Indeed, Garg et al. ${ }^{21}$ determined that there was no recurrence with gross total resection of neurenteric cysts compared with $63 \%$ in those who underwent only partial resection. However, it is noteworthy that surgeons in all three cases of intramedullary bronchogenic cysts in our literature review, as well as our own novel case, encountered difficulty in achieving complete extirpation of intramedullary components. ${ }^{18,22,23}$ This is
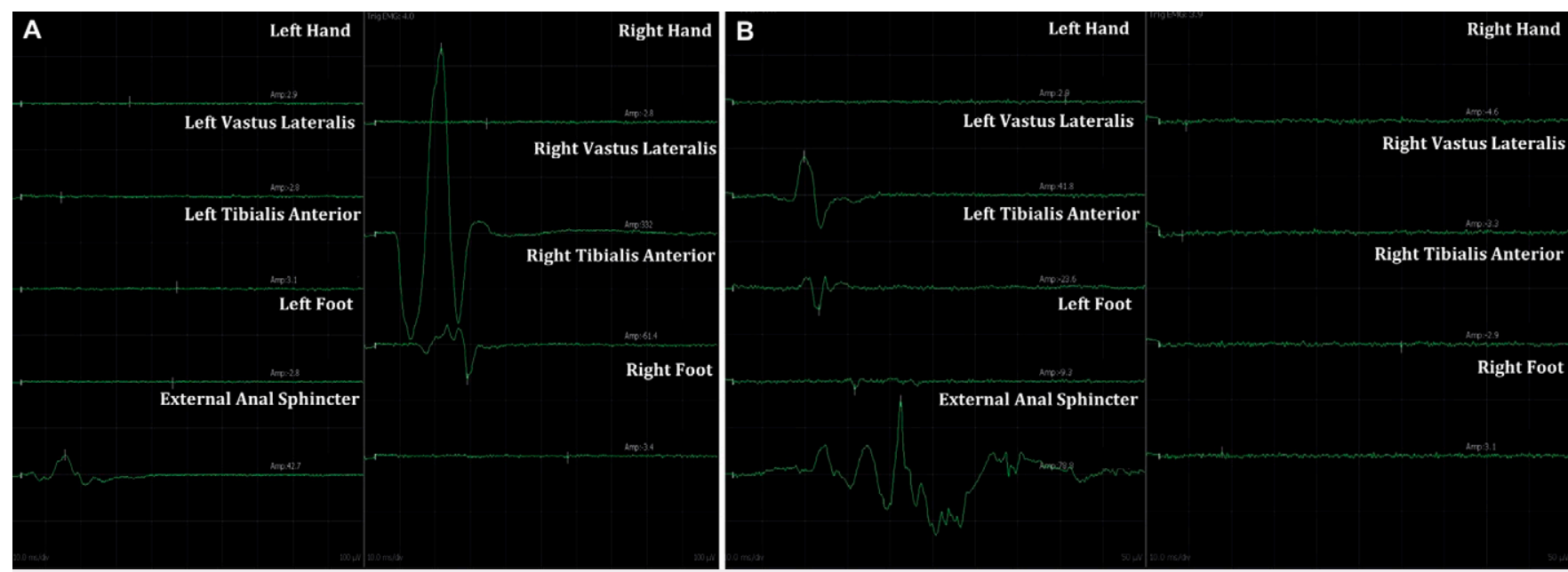

FIG. 3. Intraoperative neural monitoring demonstrates the tEMG CMAP response recorded from initial stimulation of the lesion with polyphasic responses recorded on the right vastus lateralis, right tibialis anterior, and external anal sphincter at $4 \mathrm{~mA}(\mathbf{A})$. The tEMG CMAP response recorded from stimulation of the residual lesion is displayed with polyphasic responses recorded on the left vastus lateralis, left tibialis anterior, and external anal sphincter at $4 \mathrm{~mA}$ (B). Note that the external anal sphincter responses were of higher recorded amplitudes here than initial stimulation $(40 \mu \mathrm{V}$ versus $78 \mu \mathrm{V})$. 

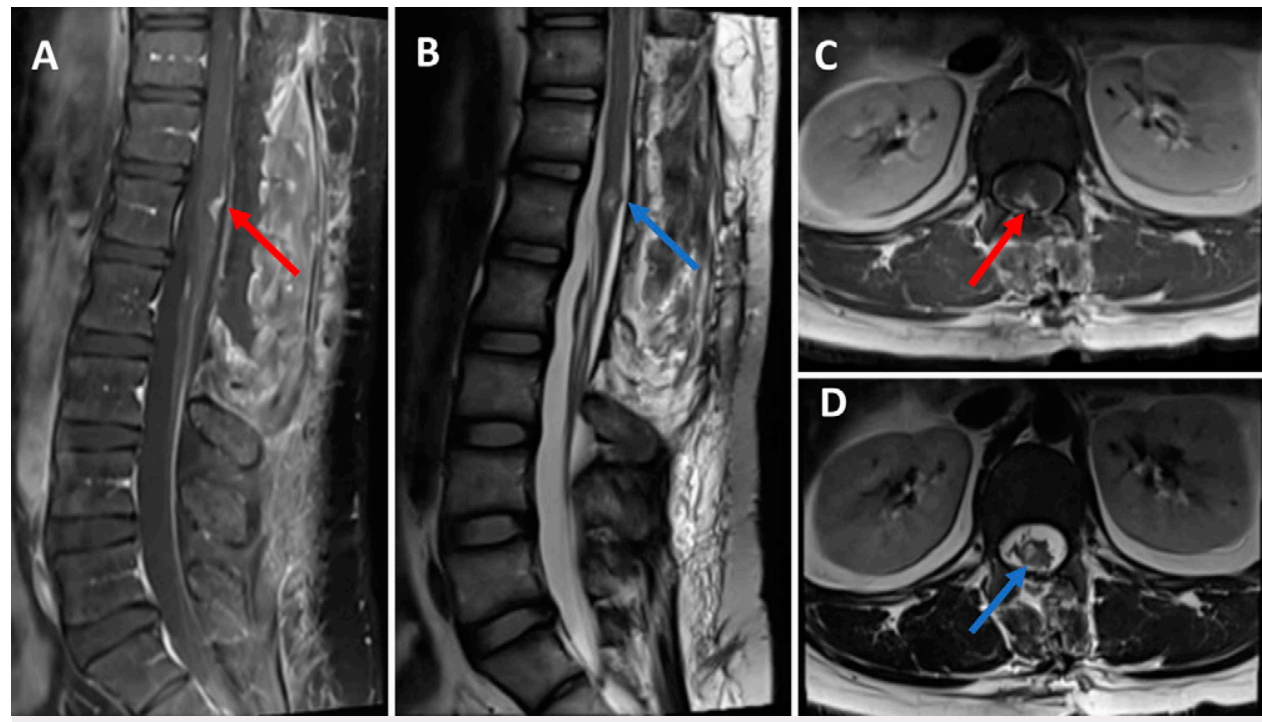

FIG. 4. Postoperative MRI of the lumbar spine showing gross total resection of the extramedullary component of the lesion on the sagittal postcontrast $\mathrm{T} 1(\mathbf{A})$ and $\mathrm{T} 2$ (B) sequences. There is residual posterior wall contrast enhancement (red arrows in $\mathbf{A}$ and $\mathbf{C}$ ) best visualized on the postcontrast T1 axial scan (C), but marked reduction in the intramedullary lesion (blue arrows in $\mathbf{B}$ and $\mathbf{D}$ ) is also visualized on the axial T2 scan (D).

due largely to the tendency for these cysts to have a tightly adherent wall to the spinal cord, precluding a clear dissection plane.

The secretory nature of these cysts predisposes patients to reaccumulation of mucinous material and therefore recurrence. As such, gross total resection would be ideal if surgically feasible. ${ }^{5,22}$ However, it is important to recognize that these lesions grow slowly due to their tight junctions between epithelial cells. ${ }^{18}$ Therefore, Rotondo et al. ${ }^{24}$ have warned of the hazards of overly aggressive resection of these intramedullary remnants. For this reason, Garg et al. ${ }^{21}$ advocated for cautious resection of recurrent cysts rather than aggressive initial resection, given that recurrence was not associated with poorer outcomes. ${ }^{25}$ This was in keeping with our management of a rare recurrent bronchogenic cyst.

\section{Lessons}

Our unique case of a simultaneously intramedullary and extramedullary bronchogenic cyst of the conus medullaris was likely a primary occurrence and supportive of the split notochord or accessory notochord embryological theory rather than the ectopic ectoderm proposal. Cautious resection of bronchogenic cysts with intramedullary extension should be performed with the use of neuromonitoring. The tightly adherent nature of these lesions usually precludes gross total resection. Although there is a tendency for

TABLE 1. Literature review of spinal intramedullary bronchogenic cysts of the conus medullaris

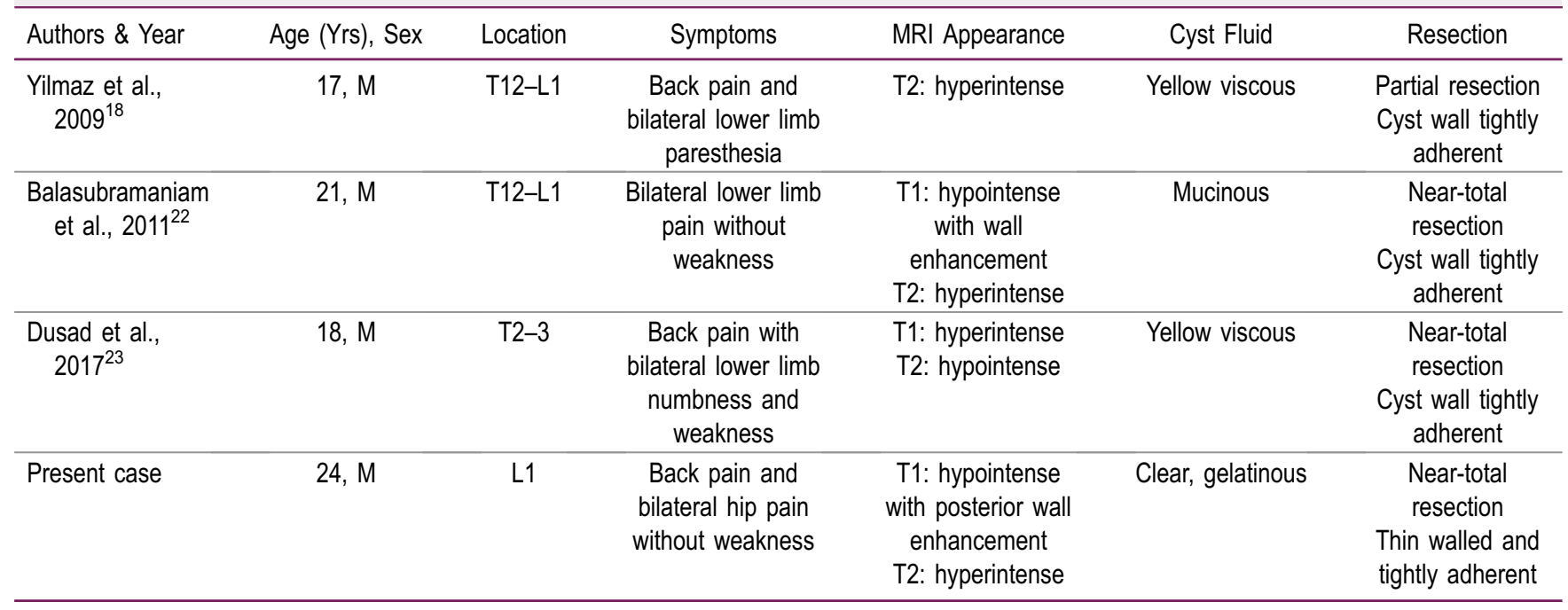


bronchogenic cyst recurrence, it is important to recognize that this is usually a rather slow process.

\section{References}

1. Bruzek AK, Kucia EJ, Oppenlander ME. Intramedullary and extramedullary cervical neurenteric cyst requiring fixation and fusion. World Neurosurg. 2016;95:621.e7-621.e12.

2. Chen J, Lai R, Li Z, et al. Case report series and review of rare intradural extramedullary neoplasms - bronchiogenic cysts. Medicine (Baltimore). 2015;94(49):e2039.

3. Aiyappan SK, Thirupathi Rajan VT, Harikrishnan V. A rare case of isolated conus medullaris neurenteric cyst. Asian J Neurosurg. 2017;12(4):715-717.

4. Kothbauer KF, Deletis V. Intraoperative neurophysiology of the conus medullaris and cauda equina. Childs Nerv Syst. 2010;26(2):247-253.

5. Baek WK, Lachkar S, Iwanaga J, et al. Comprehensive review of spinal neurenteric cysts with a focus on histopathological findings. Cureus. 2018;10(9):e3379.

6. Lippman CR, Arginteanu M, Purohit D, Naidich TP, Camins MB. Intramedullary neurenteric cysts of the spine. Case report and review of the literature. J Neurosurg. 2001;94(2 suppl):305-309.

7. Ma X, Li W, Niu C, et al. Intraspinal bronchogenic cyst: series of case reports and literature review. J Spinal Cord Med. 2017;40(2):141-146.

8. Chongyi S, Meng Y, Dejun Y, Yingjie L, Qingpeng L. Lumbar intradural extramedullary bronchiogenic cyst. Eur Surg Res. 2008;40(1):26-28.

9. Arnold PM, Neff LL, Anderson KK, Reeves AR, Newell KL. Thoracic myelopathy secondary to intradural extramedullary bronchogenic cyst. J Spinal Cord Med. 2009;32(5):595-597.

10. Ebner FH, Roser F, Acioly MA, Schoeber W, Tatagiba M. Intramedullary lesions of the conus medullaris: differential diagnosis and surgical management. Neurosurg Rev. 2009;32(3):287-301.

11. Wilkins R, Odom G. Spinal intradural cysts. Handb Clin Neurol. 1976;20(Part II):55-102.

12. Wilkinson $\mathrm{N}$, Reid $\mathrm{H}$, Hughes D. Intradural bronchogenic cysts. J Clin Pathol. 1992;45(11):1032-1033.

13. Wakao N, Imagama S, Ito Z, et al. A case of split notochord syndrome: an adult with a spinal endodermal cyst mimicking an intramedullary tumor. Neuropathology. 2011;31(6):626-631.

14. Savage JJ, Casey JN, McNeill IT, Sherman JH. Neurenteric cysts of the spine. J Craniovertebr Junction Spine. 2010;1(1):58-63.

15. Bentley JF, Smith JR. Developmental posterior enteric remnants and spinal malformations: the split notochord syndrome. Arch Dis Child. 1960;35(179):76-86.

16. Palma L, Di Lorenzo N. Spinal endodermal cysts without associated vertebral or other congenital abnormalities. Report of four cases and review of the literature. Acta Neurochir (Wien). 1976;33(3-4):283-300.

17. Zekaj E, Saleh C, Servello D. Intramedullary cyst formation after removal of multiple intradural spinal arachnoid cysts: a case report. Surg Neurol Int. 2016;7(suppl 17):S473-S474.
18. Yilmaz C, Gulsen S, Sonmez E, Ozger O, Unlukaplan M, Caner H. Intramedullary bronchogenic cyst of the conus medullaris. J Neurosurg Spine. 2009;11(4):477-479.

19. Yunoki M, Hirashita K, Gohda Y, Yoshino K, Fujimoto S, Mizobuchi K. True intraspinal neurenteric cyst in the lumbosacral region: case report. Neurol Med Chir (Tokyo). 2007;47(5): 237-239.

20. Zou M-X, Hu J-R, Kang Y-J, Li J, Lv GH, She XL. Bronchogenic cyst of the conus medullaris with spinal cord tethering: a case report and review of the literature. Int J Clin Exp Pathol. 2015;8(4):3937-3942.

21. Garg N, Sampath S, Yasha TC, Chandramouli BA, Devi BI, Kovoor $\mathrm{JM}$. Is total excision of spinal neurenteric cysts possible? $\mathrm{Br} \mathrm{J} \mathrm{Neu}$ rosurg. 2008;22(2):241-251.

22. Balasubramaniam S, Tyagi DK, Sawant HV. Intramedullary enterogenous cyst of the conus medullaris presenting as lower limb pain. J Craniovertebr Junction Spine. 2011;2(1):46-48.

23. Dusad T, Kundnani V, Dutta S, Patel A, Mehta G, Singh M. An unusual case of intradural intramedullary dorsal bronchogenic cyst in spine. J Spine Surg. 2017;3(3):514-518.

24. Rotondo M, D'Avanzo R, Natale M, et al. Intramedullary neurenteric cysts of the spine. Report of three cases. J Neurosurg Spine. 2005;2(3):372-376.

25. Felix RW, Seidel GK, Murphy EB, Rosenblum ML. Conus medullaris enterogenous cyst. PM R. 2012;4(9):698-700.

\section{Disclosures}

The authors report no conflict of interest concerning the materials or methods used in this study or the findings specified in this paper.

\section{Author Contributions}

Conception and design: Kweh, Nair. Acquisition of data: all authors. Analysis and interpretation of data: Kweh, Verhellen, Nair. Drafting the article: Kweh, Nair. Critically revising the article: Kweh, Nair. Reviewed submitted version of manuscript: Kweh, Nair. Approved the final version of the manuscript on behalf of all authors: Kweh. Administrative/ technical/material support: Kweh. Study supervision: Nair.

\section{Previous Presentation}

A portion of this paper was previously presented at the Royal Australasian College of Surgeons 2021 Annual Scientific Congress, Melbourne, Victoria, Australia, May 10-14, 2021.

\section{Correspondence}

Barry Ting Sheen Kweh: Royal Melbourne Hospital, Parkville, Victoria, Australia.barrykweh88@gmail.com. 